RICARDO MARTINS

VALLE é mestrando em Literatura Brasileira na USP e autor de diversos ensaios em revistas acadêmicas.

\section{História da Literatura}

Brasileira e Outros

Ensaios, de Joaquim Norberto de Sousa Silva, organização, apresentação e notas de Roberto Acízelo de Souza, Rio de Janeiro, Zé Mario Editor, FBN e DNL, 2002.

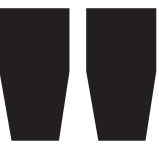

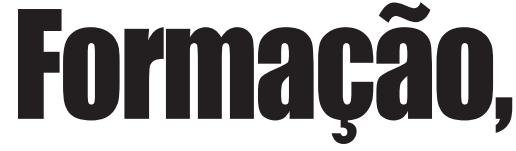

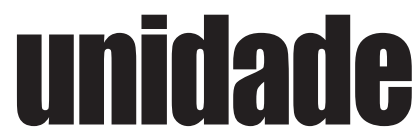

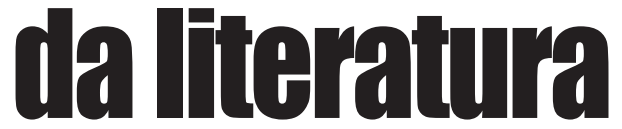

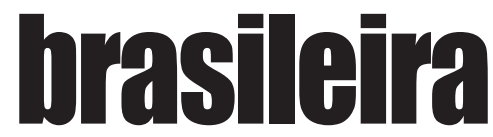

José da Gama e Castro, correspondência publicada no /ornal do Comércio, 29 de janeiro de 1842. Cf. Guilhermino César, Historiadores e Críticos do Romantismo, São Paulo/Rio de Janeiro, Edusp/LTC, 1978 p. 124
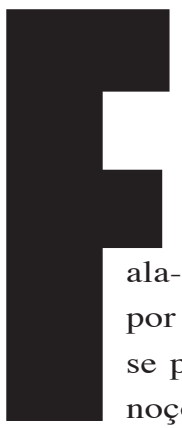

ala-se de literatura brasileira por hábito, por vício, talvez por excesso de patriotismo" (1). Eis uma provocação que se poderia repropor, a fim de relativizar a validade de noções e construtos históricos que costumam entrar em nossa reflexão como absolutos e que, com valor de realidade, de res a priori, movem-se em nossos discursos como as inquestionáveis esferas de cristal do sistema ptolomaico. Nesse sentido, formação, unidade e autonomia são categorias que, embora tenham também a sua história, têm fundamentado metafisicamente este construto do século XIX que chamamos história da literatura brasileira. Uma parte importante da documentação fundadora desta idéia, que na origem integrava um programa ideológico do Segundo Império, são os escritos de Joaquim Norberto de Sousa Silva (1820-91), pela primeira vez reunidos em livro graças ao trabalho do pesquisador Roberto Acízelo de Souza.

O volume foi intitulado pelo organizador como História da Literatura Brasileira e Outros Ensaios, dando termo a um projeto abandonado pelo autor e reconstituído pelo arquivista como se reconstitui arqueologicamente um vaso estilhaçado. A singularidade editorial desse volume, porém, é que os pedaços da peça arqueologicamente reunidos não têm uma arkhé unitária, um vaso primordial. A hipótese e o trabalho de Roberto Acízelo de Souza não são, portanto, despiciendos, porque fazem reeditar o livro jamais editado. 
Os “Outros Ensaios" reúnem tex tos dispersos, escritos entre 1840 e 1862 , entre os quais se destacam o "Bosquejo da História da Poesia Brasileira” (1840-41, pp. 277 314) e "A Língua Brasileira" (1855, pp. 339-48). O primeiro propõe uma distribuição de seis “épocas” para a poesia brasileira, concluindo com a poesia de seu tempo, isto é, coetânea da revista Niterói (1836), dos Suspiros Poéticos e Saudades (1836) de Magalhães, da circulação manuscrita d' $A$ Confederação dos Tamoios (impressa em 1857), das produções poéticas de Odorico Mendes e de tantos nomes definitivamente esquecidos para a historiografia ulterior. Sobretudo, é bom lembrar, esse "Bosquejo da História da Poesia Brasileira" não chega aos Cantos de Gonçalves Dias, que começam a sair cinco anos depois, em 1846, também integrando o movimento geral da intelectualidade constelada em torno do jovem imperador. O pequeno ensaio "A Língua Brasileira”, por sua vez, com toda a sua presumível impropriedade, esboça em meados do século XIX, já em tom polêmico, uma proposta de "língua brasileira”, essa idéia fixa que, como as moscas, sempre volta, por mais que se lhe sacuda. Mas sua proposta de "língua brasileira" não vai além - e isso mesmoé significativo-de sublinhar um ou outro aspecto distintivo em relação ao português metropolitano, sem jamais recusar a filiação e a herança lusitanas, o que está em acordo com o próprio modelo político pós-Independência, sob o qual a intelectualidade oficial se ampara e realiza "uma revolução toda literária", tendo à frente (as palavras são de Norberto) o estandarte de Magalhães, a marchar rumo à Posteridade (p. 284), que, aliás, lhe faltou com a promessa.

A parte principal do volume de Roberto Acízelo de Souzaé, porém, a reconstituição hipotética dos quatro livros planejados para a História da Literatura Brasileira de Joaquim Norberto (pp. 33-276). Sob este título são reunidos e, sobretudo, ordenados os capítulos esparsamente publicados na $R e$ vista Popular, entre 1859 e 1862, já com o fim de constituírem uma história literária. Recua duas décadas apenas o ensaio sobre o século XVII, escrito em 1843, para a Minerva Brasiliense. Do conjunto, os dois primeiros livros - "Introdução Histórica" (pp.33-163) e "Século 1(1500)" (pp. 165228) - foram publicados em segmentos avulsos, mas de maneira a preencher o plano geral de sua História da Literatura Brasileira. Nesses dois primeiros, e mais extensos, livros encontra-se o cerne do projeto literário de Norberto: na "Introdução Histórica" estão as fontes teóricas e o programa completo da poesia de sua geração, o que não deveria escapar a quem estuda Romantismo e Modernismo no Brasil; no “Século 1(1500)" estão o substrato indígena e o superestrato jesuítico que teriam dado os sólidos fundamentos das virtudes poéticas que apenas sob a pesada liberdade do Império viriam frutificar. Os outros dois livros - "Século 2o (1600)" (pp. 229-57) e “Século 3 (1700)" (pp. 259-76) - permaneceram, como tais, inéditos e, ao que parece, nem mesmo foram redigidos. Para completar o quadro, porém, o organizador optou por inserir o texto de 1843 , da $M i$ nerva Brasiliense, sobre o século XVII, e um estudo de 1862 sobre a academia dos seletos, o qual muito precariamente cobre a lacuna do século XVIII. O primeiro, no entanto, interessa pelos juízos que endossa e que transmite à posteridade como doxas críticas fortemente enraizadas hoje em certo senso comum estudioso. Norberto começa por dispor teleologicamente as guerras holandesas como prenúncio nativista dos "brasileiros" contra "a hidra da invasão holandesa”, porque “o jugo de um povo irmão era menos pesado e tolerável [sic] que o jugo de um povo estranho e conquistador" (pp. 231-2). Assim ele abre o século XVII, com "o amor da pátria, o amor da religião dos pais" impelindo os "brasileiros" às armas e, em breve, à poesia. Trata, à sua maneira, de Bento Teixeira, Gregório de Matos, Botelho de Oliveira e Bernardo Vieira Ravasco. O estilo de todos, com a exceção curiosa de Gregório, é condenado em função dos "desvarios [...] do absurdo Góngora e do alambicado Marino”, dois alvos prediletos que a reforma de Boileau visou no XVIII e constituiu um juízo que se 
transmitiria à recém-criada literarische Geschichte do XIX e às mais diversas correntes do criticism do XX. O preconceito antigongórico é compreensível dentro do modelo romântico-ilustrado (e, politicamente, liberal-monárquico) da Corte de Pedro II, ancorada nas aristocracias cautelosas do café. Para os condes Joões da neoaristocracia do capital escravista oitocentista, era incompreensível a utilidade de uma tal poesia difícil, ociosa e pedante "que produziram esses autores cujos nomes e composições nos transmitiram os editores da Fênix renascida, do Postilhão de Apolo" (p. 254); obras que, por quase três séculos, desapareceram do cenário e dos estudos literários por uma disposição historicamente deliberada de as incompreender. Já Gregório de Matos “não era para afetações, mas todo natureza, todo satírico, se bem que infelizmente todo indecência” (p. 250). A indecência de Gregório se explicava pelo "trato com inúmeras pessoas menos gradas" e fundamentava o critério que separava, judiciosamente, "as composições que ler se podem" e as que não. $\mathrm{O}$ aristocratismo liberal e católico de Norberto e de seu grupo permite compreender os seus juízos sobre a poesia aristocrática gongórica, de um lado, e sobre a obscenidade vulgar da sátira gregoriana, de outro. Por caminhos que estão para ser estudados, esses juízos sobreviveram ao tempo e chegaram até ao criticismo do século XX, descarnando-se nos currículos de letras e em certas opções didáticas, nas “áreas de concentração" dos estudos em nível superior e nas restrições editoriais a certas fontes e pesquisas, o que, no conjunto, prossegue definindo as obras que "ler se podem".

Todas as intervenções nos originais de Norberto e suas respectivas datações são anunciadas pelo organizador, o que garante à edição o cumprimento de seu papel: disponibilizar aos pesquisadores um texto confiável e historicamente situado, o que é fundamental para se fazerem as mediações que a leitura desses textos particularmente exige. Não se devem ler essas fontes oitocentistas como bibliografia secundária ou como, enfim, história literária, mas como fonte primária, “de época”: são objeto e não instrumento de estudo.

E como objeto de reflexão passo a tratá-las.

Não seria ocioso retomar a provocação inicial - "Fala-se de literatura brasileira por hábito, por vício, talvez por excesso de patriotismo". Dita em 1842, vinte anos após o golpe da Independência, dois anos após o golpe da Maioridade, seis anos após a revista Niterói, anterior aos Primeiros Cantos de Gonçalves Dias, à publicação impressa d'A Confederação dos Tamoios e de todo Alencar... -, enfim, a frase desse sr. José da Gama e Castro revela uma postura de época que certa unanimidade subseqüente apagaria. Sua argumentação fundava-se num critério lingüístico de definição de literatura e seus exemplos são, não por acaso, as literaturas alemã e italiana, que então se designam pela língua supostamente comum, a par da falta de unidade política. Com efeito, contra o critério implicitamente político do conceito de "literatura brasileira" é que o correspondente do Jornal do Comércio se coloca: a língua sendo comum, comum seria a literatura, independentemente da natureza das relações entre Brasil e Portugal. A reação de Joaquim Norberto terá fôlego de duas décadas. Esse fôlego, resultado de um imperativo político de sua época e de seu grupo, produz, treze e vinte anos depois, duas respostas que rigorosamente se contradizem. A primeira, de 1855, é o tíbio projeto de nacionalização da língua, projeto inserido numa discussão cujas proposições já tinham sido obliquamente zombadas pelo próprio Alencar no início do mesmo ano (2). A segunda resposta, que admite a identidade lingüística entre as literaturas brasileira e portuguesa, interessa-nos não pela reconstituição de uma querela intelectual, mas pelos vínculos políticos nela subentendidos. Se, para a primeira resposta, foi preciso inventar a "língua brasileira", precária, inconsistente, mais emblemática que efetiva, para a segunda, era preciso inventar a "nacionalidade brasileira" em cujo quadro entrava a constituição retroativa de três séculos e meio de "literatura brasileira". Para dar termo à discussão, Norberto invoca a autoridade, en- 
tão universal, de Chateaubriand, segundo quem a língua inglesa teria quatro literaturas - irlandesa, inglesa, escocesa e americana. Autorizando desta forma a validade do critério nacional, contra o lingüístico, Norberto reafirma e desenvolve os dois pressupostos de autenticidade poética inventados por sua geração: a paisagem e o caráter nacionais - corpo e alma do também recém-inventado Brasil. Dentro dessa perspectiva, a formação, a unidade e a autonomia da literatura brasileira correriam paralelamente à formação, unidade e autonomia do Império do Brasil, esse heilige Reich tamoio, entre duas palmeiras, laranjeiras e muitos sabiás.

Entre imperador, literatos e muitos poetas, os vínculos políticos de Joaquim Norberto são razoavelmente claros pelo que se sabe da relação de todo o seu grupo com Pedro II, principalmente no âmbito do Instituto Histórico e Geográfico Brasileiro. Entretanto, o mapeamento dos vínculos programáticos e intelectuais de sua História da Literatura Brasileira é trabalho que está por ser feito. Um desses vínculos já se revela pela autoridade invocada para a refutação do critério lingüístico: o autor do Génie du Christianisme. O Vicomte de Chateaubriand e a Mme. de Staël, segundo Norberto, teriam criado "a nova escola do cristianismo”(p. 309), o Romantismo, que, no Brasil, viria a encontrar um solo forçosamente fértil, já que "a poesia sublime do cristianismo [...] santificou as primeiras fundações dos portugueses" (p. 153, citando Santiago Nunes Ribeiro). O vínculo programático a esse Romantismoé que endossava, na especificidade brasileira, o extermínio dos tão louvados indígenas, que, "conquistados, submetidos ao jugo, desapareceram de sobre a face da terra, como desapareceram as nações belicosas. / Então vieram novos brasileiros..." (p. 281). Apaga-se a violência pela suposta naturalidade do extermínio desses povos belicosos graças à santa fé e ao pacífico progresso: eis a universalidade suposta no curso da história da nossa nacionalidade.

O sentido deste e de outros vínculos intelectuais poderá ser esclarecido e apro- fundado pelo estudo detido das longas e inúmeras citações que tantas vezes fazem dos ensaios de Norberto uma compilação interessada da erudição específica que circulou nos meios letrados dos anos 40, 50 e 60 do século XIX no Brasil. É o caso, por exemplo, da apropriação católica e monárquica do Iluminismo francês ou ainda da introdução, por via indireta, do Idealismo alemão, a "escola histórica de $\mathrm{He}$ gel", na raiz do pensamento romântico brasileiro. Mas o estudo dessas relações, o mapeamento dessas fontes e a avaliação dos efeitos dessa circulação indireta é trabalho que está para ser feito e que o volume de que tratamos aqui possibilita.

Em traços grossos, pode-se dizer que a obra de Joaquim Norberto é o cumprimento do programa entusiasticamente sugerido em 1826 por Ferdinand Denis, nas últimas páginas do Résumé de l'Histoire Littéraire du Brésil. Como a execução do programa de Denis não foi unívoca, cabe anotar que o projeto literário em que Norberto se insere não se alinha ao de Alencar, que, em última instância, também se enraíza no texto do brasilianista francês. Desde 1841 , seus escritos têm como suma execução da proposta de Denis A Confederação dos Tamoios, o inglório poema épico do louvado "gênio fluminense"; poema cujos quatro primeiros cantos já estavam escritos em 1841 e cuja redação completa provavelmente já circulava manuscrita antes de 44 entre os protegidos do rei, segundo se pode deduzir dos documentos reeditados por Roberto Acízelo de Souza. Também pelo prisma teórico de Gonçalves de Magalhães é que Norberto lê todas as fontes teóricas nacionais e estrangeiras, seguindo sempre de perto o "Ensaio sobre a História da Literatura do Brasil", publicado em 1836 na revista Niterói pelo mesmo "chefe de uma revolução toda literária"; texto-chave que Norberto ora cita, ora glosa, sempre com dicção muito singela e destituída de malícia. Nisso mesmo, aliás, cumpre o tom programático do ilustrado imperador, romântico-ameno-castiço, e do imperador ilustrado, liberal-moderadoescravista. Essa ingenuidade deslocada tem, 
portanto, um fundo perverso. A amenidade da prosa por-que-me-ufano de Joaquim Norberto se fazia sobre a ampla liteira da economia escravista, sob a novíssima Petrópolis e a par de pesados incentivos à migração européia, para higiene étnica do novo Império. Não é possível, portanto, identificar-se hoje com as suas mesmas causas. E é de admirar que, na busca da unidade da autonomia da literatura brasileira, ainda haja quem aplique sistematicamente os mesmos princípios fundadores desse Romantismo brasiliense: a paisagem e o caráter nacionais; princípios questionáveis não por serem românticos, mas por representarem os pilares de uma idéia civilizatória de "literatura brasileira", e segundo um modelo de civilização escravocrata, monarquista e católico. Infelizmente, são ainda os critérios da paisagem e do caráter que orientam muitos dos discursos críticos que, no final do século XX e início do XXI, pretendem descrever e fixar a formação, a unidade e a autonomia dessa nossa literatura. E o infelizmente disso não está na relatividade abstrata do critério teórico-metodológico adotado. É infelicidade que, com esses critérios, perpetue-se a estreiteza programática desse "nós", implícito na nossa história literária. É como se nunca lêssemos o Triste Fim de Policarpo Quaresma até o fim e ficássemos com a caricatura e com as essências ideais que definem o perigoso conceito de pátria.

Um último elogio é necessário fazer ao pesquisador carioca que nos disponibilizou essa documentação importantíssima: ele não adere ao seu objeto de estudo, avaliando com precisão o material que editou: "a produção de Norberto está muito longe de distinguir-se pelo vigor conceitual, consistindo apenas no desenvolvimento - sempre numa linguagem declamatória [...] de algumas idéias-chave de certa face do pensamento romântico". E mais adiante:

3 As palavras são de Mário de Andrade e delas tomamos aqu o caráter apostático apenas. Cf. "O Movimento Modernis ta", in Mário de Andrade, As pectos da Literatura Brasileira 5a ed., São Paulo, Martins, 1974 , p. 255.
"Dessas noções que afinal se sobrepõem e se confundem - nacionalidade/originalidade-derivam por sua vez duas outras: natureza nacional como fonte de inspiração; congruência entre história, usos e costumes nacionais e respectiva literatura. Se acrescentarmos agora à seqüência de seu ponto de vista - nacionalidade/originalidade/natureza e costumes nacionais - a convicção de uma [...] 'tendência dos selvagens brasileiros para a poesia', bem como certo tradicionalismo católico um tanto ancien régime e muito ibérico [...] teremos resumido o âmbito acanhado em que se movem os argumentos de Norberto" (pp. 24-5).

Os documentos disponibilizados pela edição de Roberto Acízelo de Souza abrem caminho para o debate, desde que não haja aderência prévia, o que muitas vezes dilui as fronteiras entre o leitor crítico e seu objeto de estudo. Temos muitas vezes nos estudos literários o vício das aderências afetivas. Por isso, quando se estuda a "literatura brasileira" ou mesmo "o Brasil", talvez seja preciso antes de tudo não amá-los, como Joaquim Norberto os amou, para que a ingenuidade e os afetos, fora de lugar, não endossem a perversão universal (hoje, enfim, globalizada). O discurso aparentemente ingênuo de Joaquim Norberto estava em seu próprio lugar, porque integrava e construía um modelo político que o amparava. Se aquele modelo já não tem validade histórica, direcionemos a ele apenas o interesse pela matéria passada, mas tenham os nossos afetos outros objetos. Do contrário, fazendo sempre o elogio das "conquistas" românticas, das "conquistas" modernistas, das "conquistas" da "nossa atualidade, da nossa nacionalidade, da nossa universalidade" (3), o discurso crítico segue reproduzindo a ideologia ostensivamente liberal e racista que, desde o século XIX, orientou o modelo de progresso nacional que dura para além do malfadado jubileu de 500 anos de "conquista" portuguesa; modelo que os escritos de Norberto documentam emblematicamente. A atitude intelectual que, ainda hoje, perscruta as raízes remotas da unidade e autonomia literárias do Brasil escamoteia a exclusão historicamente inerente a esses conceitos. Permanece, enfim, limitada à "revolução toda literária", de que fala Norberto, e como que sentada na beira do caminho, espiando a multidão passar. 